\title{
Whole gene expression profile in blood reveals multiple pathways deregulation in R6/2 mouse model
}

\author{
Daniela Diamanti ${ }^{1 *}$, Elisa Mori ${ }^{1}$, Danny Incarnato ${ }^{2}$, Federico Malusa $^{1}$, Costanza Fondelli $^{1}$, Letizia Magnoni ${ }^{1}$ \\ and Giuseppe Pollio ${ }^{1}$
}

\begin{abstract}
Background: Huntington Disease (HD) is a progressive neurological disorder, with pathological manifestations in brain areas and in periphery caused by the ubiquitous expression of mutant Huntingtin protein. Transcriptional dysregulation is considered a key molecular mechanism responsible of HD pathogenesis but, although numerous studies investigated mRNA alterations in HD, so far none evaluated a whole gene expression profile in blood of R6/ 2 mouse model.

Findings: To discover novel pathogenic mechanisms and potential peripheral biomarkers useful to monitor disease progression or drug efficacy, a microarray study was performed in blood of R6/2 at manifest stage and wild type littermate mice. This approach allowed to propose new peripheral molecular processes involved in HD and to suggest different panels of candidate biomarkers. Among the discovered deregulated processes, we focused on specific ones: complement and coagulation cascades, PPAR signaling, cardiac muscle contraction, and dilated cardiomyopathy pathways. Selected genes derived from these pathways were additionally investigated in other accessible tissues to validate these matrices as source of biomarkers, and in brain, to link central and peripheral disease manifestations.

Conclusions: Our findings validated the skeletal muscle as suitable source to investigate peripheral transcriptional alterations in $\mathrm{HD}$ and supported the hypothesis that immunological alteration may contribute to neurological degeneration. Moreover, the identification of altered signaling in mouse blood enforce R6/2 transgenic mouse as a powerful HD model while suggesting novel disease biomarkers for pre-clinical investigation.
\end{abstract}

Keywords: Huntington disease, R6/2, Gene expression, Blood

\section{Background}

Huntington disease (HD) is an autosomal dominant neurodegenerative disorder characterized by progressive atrophy of specific brain areas with consequent alterations of motor and cognitive functions, including psychiatric disturbances, weight loss, as well as metabolic, neuroendocrine and immunological alterations [1-3]. The cause of this fatal disease is an aberrant expansion of CAG trinucleotide in the exon 1 of $H T T$ gene, translating into a

\footnotetext{
* Correspondence: ddiamanti@sienabiotech.it

${ }^{1}$ Siena Biotech S.p.A., strada del Petriccio e Belriguardo, Siena 35, 53100, Italy
} Full list of author information is available at the end of the article gain-of-function and loss-of-function to wild type huntingtin protein. In healthy individuals, CAG number is included in the range of 6 to 26, while HD patients have more than 36 Gln stretch [1] with an inverse relationship between polyQ length and the age of onset. The aberrant polyQ tract results in Huntingtin protein misfolding, which generates insoluble intracellular inclusions and aggregates, important hallmarks of the disease.

Despite extraordinary efforts in understanding the HD pathogenesis, the exact molecular mechanisms responsible for this devastating disorder are still unknown and probably multiple parallel processes may contribute, representing potential therapeutic targets [4,5]. Striking evidences support an important role of transcriptional abnormalities in HD

\section{Biomed Central}


pathogenesis [6]. Mutant Huntingtin protein (mut-HTT) and its aggregates could modulate gene transcription by entering the nucleus and altering the transcriptional machinery either directly, through DNA binding [7], or sequestering important transcription factors [8].

Even though no animal models currently in use encompass all disease features, transgenic mice carrying either full length or mut-HTT fragments represent an invaluable instrument to study pathological mechanisms and to test efficacy and toxicity of small molecules in pre-clinical settings [9-11]. Numerous behavioral and neurological symptoms similar to what seen in HD patients have been also observed in transgenic mouse models [11,12] including those expressing only short fragments of mut-HTT, as R6/2 mice [13]. R6/2 is one of the first HD transgenic mouse model created, expressing only the N-terminal fragment of HTT (exon 1) and it is characterized by short survival and development of pathological features mimicking human stages of disease $[13,14]$. For this reason, transcriptional and behavioral alterations have been intensely studied in $\mathrm{R} 6 / 2$, which has being commonly employed not only in pre-clinical drug testing but also in peripheral investigations, often realized in parallel with HD patients $[15,16]$. Stemming from those observations, although HD is mainly a CNS disorder, ubiquitous expression of both normal and mut-HTT in the whole body [17] has moved the attention toward peripheral dysfunctions, increasing the knowledge on HD etiology and other disease manifestations, and aiding the finding of new biomarkers $[18,19]$, as evidenced by the flourishing number of transcriptional and proteomic studies conducted in HD blood [16,20-24].

In this study, we investigated transcriptional dysregulations occurring in R6/2 and wild type littermate mouse blood to reinforce previous observations derived from human studies and to discover novel pathological processes and candidate biomarkers, useful in pre-clinical investigations and in designing therapeutic trials. The transcriptional alterations detected in blood were also analyzed in brain to identify a possible link with central pathological mechanisms, and in other peripheral tissues, like skeletal muscle and skin, to validate them as additional sources of potential biomarkers.

\section{Findings}

\section{Primary analysis of microarrays}

To discover differential peripheral gene expression between R6/2 and WT littermate mice, blood samples were collected at 16 weeks of age, when mutant mice were starting to show neurological signs of decline, like abnormal motor behavior and body weight loss, all characteristics of symptomatic state of the HD pathology. Transcriptional investigation was carried through a microarray study performed on individual blood sample of four R6/2 and three WT mice. Microarray analysis showed approximately 2200 transcripts significantly modulated between R6/2 and WT mice, according to selection criteria of p-value (p) lower than 0.05 and absolute fold change (abs FC) higher than 1.3 (Figure 1A). Among these, 1072 probe sets were up-regulated and 1164 were down-regulated. A limited number of transcripts (133) resulted significantly altered in blood with a $\mathrm{p}<0.05$ and high FC (abs FC $>2$ ). A selection of these most differentially expressed $(\mathrm{p}<0.001$; abs $\mathrm{FC}>2)$ genes are reported in Figure 1B.

\section{GSEA analysis of differentially expressed genes}

In order to highlight relevant processes that could be altered in blood, we applied Gene Set Enrichment Analysis (GSEA) method on the same dataset. This computational method identifies groups of genes with modest but coordinate changes in the expression between phenotypes by utilizing all transcripts of a microarray dataset and discovering significant differences in terms of pathways or gene sets associated with a particular biological function. Microarray analysis was performed using KEGG, BioCarta and Reactome pathway collections of MSigDB and was enforced by Biological Processes of GeneOntology.

Analyzing KEGG, 92 gene sets resulted up-regulated and 77 down-regulated in mutant mice with respect to wild type mice, and among them, 19 pathways were significantly enriched in $\mathrm{R} 6 / 2$, while 2 were significantly enriched in wild type, having FDR $<25 \%$ (Table 1 ). Reactome database, which contains a wider number of gene sets with respect to KEGG, showed a total number of 309 up-regulated collections, 14 of them with FDR < $25 \%$, and 169 down-regulated collections, but none with a significant modulation (Table 1). By using BioCarta significant modulations were revealed only in 3 upregulated gene sets among 79 positively regulated and 57 negatively regulated (Table 1 ).

Similar findings were obtained by analyzing entire microarray expression dataset in terms of biological processes of GeneOntology collections. In particular, 20 of these differentially modulated processes were linked to metabolism (Additional file 1: Table S1). Results confirmed alteration of metabolic processes in mutant mice as well as coagulation impairment and amino acid, lipid and fatty acid metabolism dysfunctions. Moreover, regulation of muscle and heart contraction processes emerged among enriched processes in WT mice.

To understand information derived from GSEA, we analyzed in details pathways markedly modulated in KEGG database, focusing on the two top enriched collections in R6/2, namely "complement and coagulation cascade" and "PPAR signaling", together with the two 


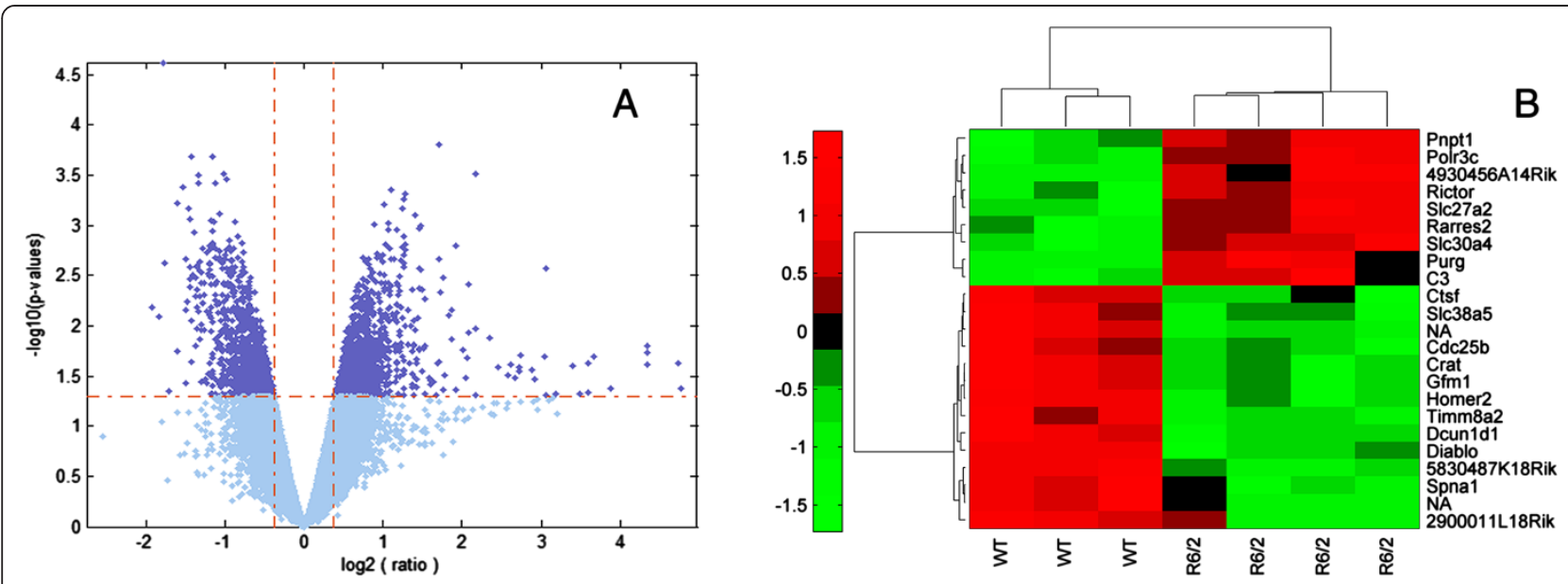

Figure 1 Microarray results. Figure shows results of microarray analysis performed on four R6/2 versus three WT mice using LIMMA package: (A) Volcano plot shows the - $\log 10$ of p-values against the genes biological effect expressed as log 2 transformed fold change. Cutoff values are set to $p<0.05$ and abs FC $>1.3$. (B) Bi-dimensional cluster (obtained by using correlation and Euclidean distances between genes and strains, respectively, and applying average linkage method) shows the 23 most significant differentially expressed probe sets $[p<0.001$ and abs FC $>2]$.

top enriched collections in WT mice, that are "cardiac muscle contraction" and "dilated cardiomyopathy", emphasizing existing relationships with HD pathology.

\section{Complement and coagulation cascade}

Complement and coagulation cascade pathway resulted altered in R6/2 mice in the three database employed with GSEA. Pathway core enrichment obtained from our analysis comprised numerous components of complement system and serpins, as well as many coagulation factors, that resulted up-regulated in blood of R6/2 mice with respect to WT (Figure 2; detailed core enrichment in Additional file 2: Table S2).

The complement system is involved in the first line of host defense against pathogens [25]. Consisting of soluble and membrane embedded proteins, it is a component of the innate immune response, that acts in peripheral tissues and in the brain. Although a protective role linked to clearance of cellular debris has been assigned to several components of the cascade, a relevant effect of its activation in brain is that it may contribute to neuro-inflammation and neuronal loss in neurodegenerative disorders as HD and Alzheimer's disease [26]. Indeed, an increased number of works debate on the immune system activation in HD [2,27]. Most of them are focused on the complement cascade impairment by accurate investigations at transcriptional and proteomic level, both in blood and brain, to discover potential biomarkers or causative factors of the pathology, respectively $[19,23,28]$. Here, we discovered for the first time transcriptional alteration of numerous components of the complement system in whole blood of an HD mouse model at manifest stage. Although previous transcriptional studies conducted in HD patients blood
$[20,21]$ did not report abnormalities of this pathway, our findings agree with a multi-approaches proteomic investigation performed in HD human plasma samples [23]. In Dalrymple et al. [23], several proteins including some complement components, as $\mathrm{C} 9$, were identified as possible disease progression biomarkers, confirming the involvement of acute-phase response and consequent activation of complement cascade in HD patients. In our investigation, no significant alteration of interleukins and cytokines mRNAs was observed in R6/2 blood at this stage, differently from what has been measured in plasma of HD patients and serum of HD animal models $[19,29]$.

The identification of complement and coagulation cascade signaling in murine blood may enforce R6/2 transgenic mouse as HD model to discover pharmacodynamic and disease peripheral biomarkers useful in pre-clinical investigation. Moreover, recent evidences focusing on druggability of pathway components [30,31], evaluated complement factors as potential targets for the treatment of autoimmune and inflammatory diseases, including neurodegenerative disorders.

\section{PPAR signaling}

Considering KEGG database results, PPAR signaling was the second best enriched pathway in mutant mice. This is intrinsically linked to other downstream processes emerging in the KEGG list of R6/2 up-regulated pathways, such as primary bile acid biosynthesis, biosynthesis of unsaturated fatty acids and fatty acid metabolism, or other pathways related to amino acid metabolism or synthesis (Table 1). Additionally, most of them resulted modulated in the analysis performed by Reactome database (Table 1). A similar metabolic profile was also 
Table 1 GSEA canonical pathways results on three different database (KEGG, Reactome and BioCarta)

\begin{tabular}{|c|c|c|c|c|c|c|c|}
\hline & Gene set name & SIZE & ES & NES & NOM p-val & FDR q-val & FWER p-val \\
\hline \multirow[t]{21}{*}{ KEGG } & COMPLEMENT AND COAGULATION CASCADES & 61 & 0.69 & 2.56 & 0.000 & 0.000 & 0.000 \\
\hline & PPAR SIGNALING PATHWAY & 60 & 0.56 & 2.02 & 0.000 & 0.004 & 0.006 \\
\hline & GLYCINE SERINE AND THREONINE METABOLISM & 29 & 0.60 & 1.87 & 0.002 & 0.023 & 0.057 \\
\hline & PRIMARY BILE ACID BIOSYNTHESIS & 15 & 0.69 & 1.77 & 0.006 & 0.044 & 0.137 \\
\hline & RIBOSOME & 82 & 0.45 & 1.73 & 0.000 & 0.052 & 0.199 \\
\hline & LYSINE DEGRADATION & 43 & 0.48 & 1.63 & 0.007 & 0.126 & 0.483 \\
\hline & HISTIDINE METABOLISM & 28 & 0.53 & 1.62 & 0.020 & 0.110 & 0.488 \\
\hline & SYSTEMIC LUPUS ERYTHEMATOSUS & 54 & 0.46 & 1.62 & 0.007 & 0.101 & 0.505 \\
\hline & PEROXISOME & 73 & 0.43 & 1.60 & 0.002 & 0.105 & 0.565 \\
\hline & PENTOSE PHOSPHATE PATHWAY & 23 & 0.55 & 1.59 & 0.013 & 0.100 & 0.582 \\
\hline & BUTANOATE METABOLISM & 30 & 0.51 & 1.59 & 0.007 & 0.095 & 0.598 \\
\hline & CYSTEINE AND METHIONINE METABOLISM & 33 & 0.47 & 1.54 & 0.026 & 0.131 & 0.736 \\
\hline & BIOSYNTHESIS OF UNSATURATED FATTY ACIDS & 18 & 0.55 & 1.53 & 0.035 & 0.134 & 0.770 \\
\hline & TYROSINE METABOLISM & 35 & 0.46 & 1.51 & 0.031 & 0.144 & 0.822 \\
\hline & PRION DISEASES & 32 & 0.47 & 1.51 & 0.024 & 0.140 & 0.831 \\
\hline & ONE CARBON POOL BY FOLATE & 16 & 0.55 & 1.47 & 0.043 & 0.177 & 0.910 \\
\hline & SELENOAMINO ACID METABOLISM & 25 & 0.48 & 1.46 & 0.047 & 0.171 & 0.916 \\
\hline & FATTY ACID METABOLISM & 33 & 0.45 & 1.44 & 0.047 & 0.193 & 0.948 \\
\hline & AMINOACYL TRNA BIOSYNTHESIS & 41 & 0.42 & 1.40 & 0.048 & 0.241 & 0.977 \\
\hline & CARDIAC MUSCLE CONTRACTION & 69 & -0.5 & -1.83 & 0.000 & 0.044 & 0.051 \\
\hline & DILATED CARDIOMYOPATHY & 87 & -0.46 & -1.74 & 0.000 & 0.075 & 0.163 \\
\hline \multirow[t]{14}{*}{ REACTOME } & FORMATION OF FIBRIN CLOT CLOTTING CASCADE & 31 & 0.7 & 2.20 & 0.000 & 0.002 & 0.001 \\
\hline & BILE ACID AND BILE SALT METABOLISM & 23 & 0.73 & 2.18 & 0.000 & 0.001 & 0.001 \\
\hline & COMPLEMENT CASCADE & 23 & 0.71 & 2.10 & 0.000 & 0.003 & 0.007 \\
\hline & LIPOPROTEIN METABOLISM & 26 & 0.67 & 2.05 & 0.000 & 0.007 & 0.019 \\
\hline & RESPONSE TO ELEVATED PLATELET CYTOSOLIC CA2 & 74 & 0.53 & 2.01 & 0.000 & 0.010 & 0.034 \\
\hline & CHYLOMICRON MEDIATED LIPID TRANSPORT & 16 & 0.73 & 2.00 & 0.000 & 0.009 & 0.039 \\
\hline & INTRINSIC PATHWAY & 17 & 0.73 & 1.99 & 0.000 & 0.008 & 0.040 \\
\hline & METABOLISM OF AMINO ACIDS AND DERIVATIVES & 188 & 0.45 & 1.98 & 0.000 & 0.009 & 0.052 \\
\hline & LIPID DIGESTION MOBILIZATION AND TRANSPORT & 41 & 0.58 & 1.95 & 0.002 & 0.011 & 0.070 \\
\hline & SYNTHESIS OF BILE ACIDS AND BILE SALTS & 18 & 0.69 & 1.91 & 0.004 & 0.016 & 0.109 \\
\hline & SULFUR AMINO ACID METABOLISM & 24 & 0.61 & 1.84 & 0.002 & 0.035 & 0.239 \\
\hline & PEPTIDE CHAIN ELONGATION & 81 & 0.45 & 1.74 & 0.000 & 0.094 & 0.548 \\
\hline & CLEAVAGE OF GROWING TRANSCRIPT IN THE TERMINATION REGION & 31 & 0.51 & 1.63 & 0.011 & 0.238 & 0.888 \\
\hline & TRANSCRIPTIONAL ACTIVITY OF SMAD2 SMAD3 SMAD4 HETEROTRIMER & 36 & 0.49 & 1.62 & 0.007 & 0.248 & 0.917 \\
\hline \multirow[t]{3}{*}{ BIOCARTA } & COMP PATHWAY & 16 & 0.75 & 2.02 & 0.000 & 0.021 & 0.017 \\
\hline & INTRINSIC PATHWAY & 23 & 0.67 & 2.00 & 0.000 & 0.012 & 0.019 \\
\hline & TOB1 PATHWAY & 19 & 0.61 & 1.70 & 0.011 & 0.224 & 0.412 \\
\hline
\end{tabular}

Table shows statistically up-regulated and down-regulated pathways in R6/2 versus WT mice, and for everyone, number of genes (size) identified in the microarrays, enrichment score (ES), normalized enrichment score (NES), nominal p-value (NOM p-val), false discovery rate (FDR q-val), familywise-error rate (FWER p-val).

described in serum of HD patients and in an HD murine model [24].

Peroxisome proliferator-activated receptors, PPARs, belong to the nuclear hormone receptor family, comprising
PPARa, PPARg, PPARb/d, and are localized in different tissues where they influence distinct processes. PPARs are ligand-depend transcription factors that form heterodimeric complexes with retinoid-X-receptor RXR, 


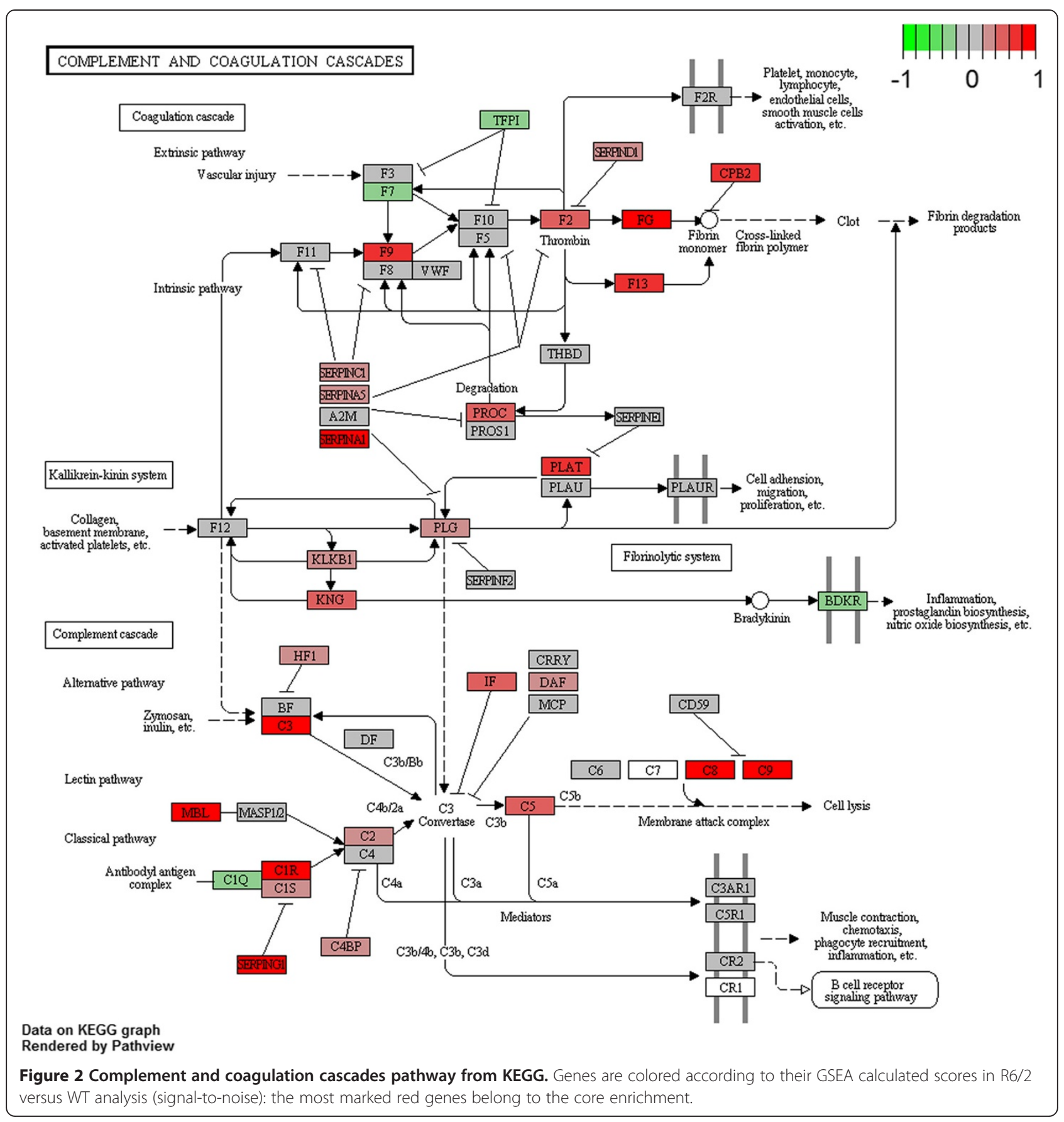

and regulate the expression of target genes involved in carbohydrate, amino acid and lipid metabolism. Figure 3 shows target genes altered in R6/2 blood and belonging to PPAR signaling core enrichment and cognate downstream processes (detailed core enrichment in Additional file 3: Table S3). The impairment of this signaling has been already seen in different tissues of HD patients and models [32]. It can be noted that many of the genes that contribute to enrich this collection are apolipoproteins, fatty acid binding proteins, $C Y P$ genes as well as the same PPARs and RXR. In particular, GSEA revealed adipose tissue dysfunction and adipocitokine signaling alteration that have been already detected in R6/2 mice, where reduced adipokine levels and PPARg target genes linked to adipocyte function and differentiation were observed [33].

The other metabolic processes that emerged as altered in R6/2 blood are well-known for being deregulated in HD. Indeed, we found lipid-linked signaling like fatty acids, bile acids and cholesterol metabolism. Altered cholesterol pathway and its biosynthesis were deeply 


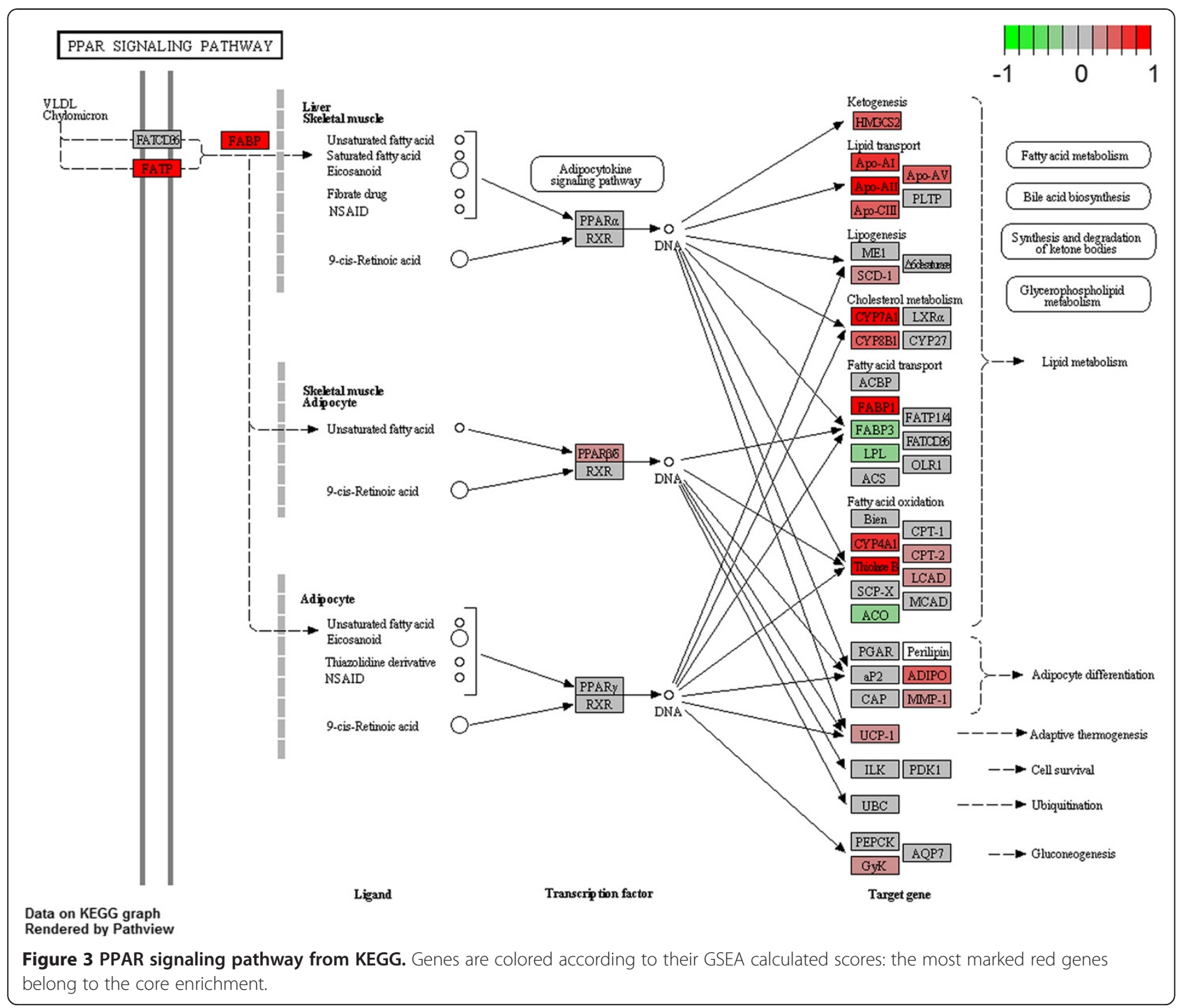

investigated by Cattaneo and collaborators [34] in patients and animal models, both in peripheral tissues and in CNS [35], demonstrating that cholesterol might have a pivotal role in HD pathogenesis. Moreover, cholesterol dysfunction is closely associated with lipid, triglyceride and fatty acid metabolism that are also impaired in HD [36]. In conclusion, evidences of PPAR signaling impairment in R6/2 blood, mirroring numerous HD systemic metabolic abnormalities [3], may contribute to the identification of new pathogenic mechanisms. Drugs against lipid dysregulation have been already tested in HD and they should be supported by disease biomarkers as PPAR target genes, to monitor therapeutic efficacy.

\section{Cardiac muscle contraction and dilated cardiomyopathy}

Among all 77 gene set collections enriched in wild type phenotype within KEGG database, only two resulted significantly modulated: dilated cardiomyopathy and cardiac muscle contraction pathways (Figure 4 and 5). Interestingly, other similar pathways (hypertrophic cardiomyopathy and arrhythmogenic right ventricular cardiomyopathy) appeared in the list of modulated collections but with FDR $>25 \%, \mathrm{p}<0.1$. In resulting GSEA core enrichment of cardiac muscle contraction (Figure 5; Additional file 4: Table S4), we found genes linked to calcium efflux and voltage (Slc8a1, Cacna1f, Cacng1, Cacng3, Cacna1s and Cacng6), or expressed in mitochondria and involved in oxidation-reduction processes (Cox6b2, Cox7b2, Cox6a2 and Cox7a1) as well as genes contributing to the structural integrity of muscle fibers (Myh7, Myh6, My13 and My12). Moreover, in dilated cardiomyopathy pathway core enrichment (Figure 4; Additional file 5: Table S5), integrins (Itga1, Itga10, Itga8 and Itgb6) and cellular components of troponin system (Tnni3, Tnnc1 and Tnnt2) appeared modulated, besides Cox and Myh genes. 


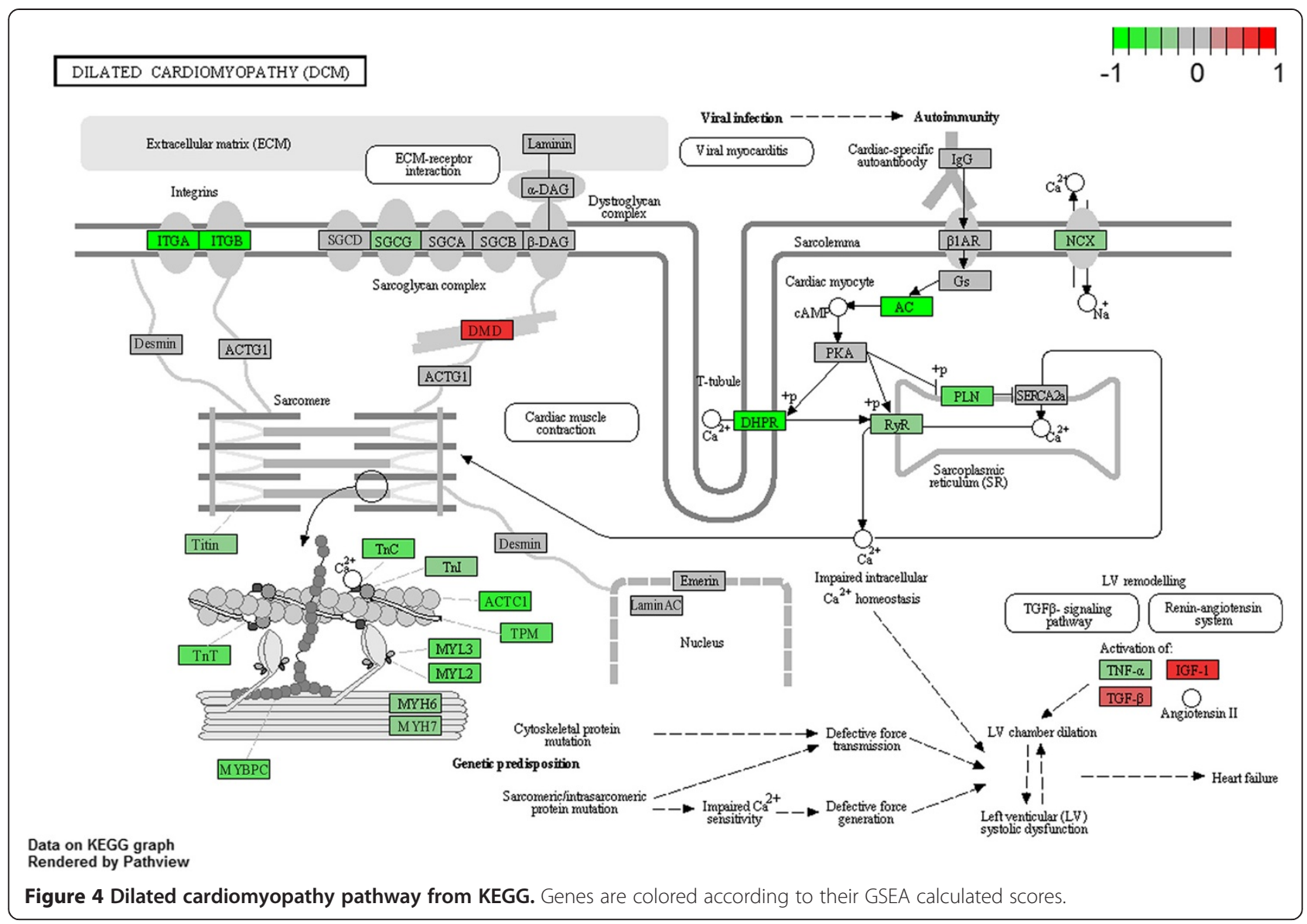

The two processes found down-regulated in R6/2 blood are related to heart contraction performance, which is monitored by cardiac myocytes excitation with the maintenance of cellular homeostasis through $\mathrm{Na}^{+}$and $\mathrm{Ca}^{2+}$ fluxes. $\mathrm{Ca}^{2+}$ homeostasis imbalance is considered a relevant cause of many neurodegenerative disorders, including HD $[37,38]$, where impairment of $\mathrm{Ca}^{2+}$ physiological equilibrium is generally followed by progressive heart failure and sudden cardiac death. Additionally, $\mathrm{Ca}^{2+}$ handling defects may exacerbate mitochondrial dysfunctions $[39,40]$, considered being a relevant mechanism in HD pathogenesis [41], and hence contributing to cardiac failure too [42].

A fascinating remark is that, even if our data were generated from a whole genome expression analysis performed in blood, modulation of these two pathways suggests evidences of cardiac dysfunction in R6/2 mice. Nevertheless, although Huntington's disease is a neurological disorder, cardiac failure is an important cause of death in a high percentage of HD patients (over 20\%) [43]. In addition, a recent work showed direct evidences of cardiac dysfunction in R6/2 [44], highlighting an in-vivo impairment of numerous cardiac functions, including myocardial contractility. Our finding agree with what has been previously demonstrated by Mihm et al. [45], about cardiotoxic effects coming from peripheral mut-HTT expression. This study displayed that mut-HTT expression in R6/2 cardiomyocytes could result in severe cardiac systolic and diastolic impairment, showing parallel changes between cardiac and neurological symptoms, and suggesting the use of cardiovascular performance indicators as "state biomarkers" of disease progression. Here, we identified for the first time in HD blood a set of deregulated genes involved in cardiac pathophysiology that should be useful to monitor a drug therapy addressing this HD symptom. Peripheral blood gene expression profiling has been already applied to assess some cardiovascular diseases, as myocardial infarction [46] relying on the ability of blood to operate as a sensor able to capture physiological and pathological modifications, transforming them in gene expression changes [47].

\section{RT-qPCR}

To validate microarray results derived from GSEA, we tested the expressions of selected genes in blood samples through RT-qPCR. For this purpose, mouse blood samples were pooled as indicated in methods section. This 


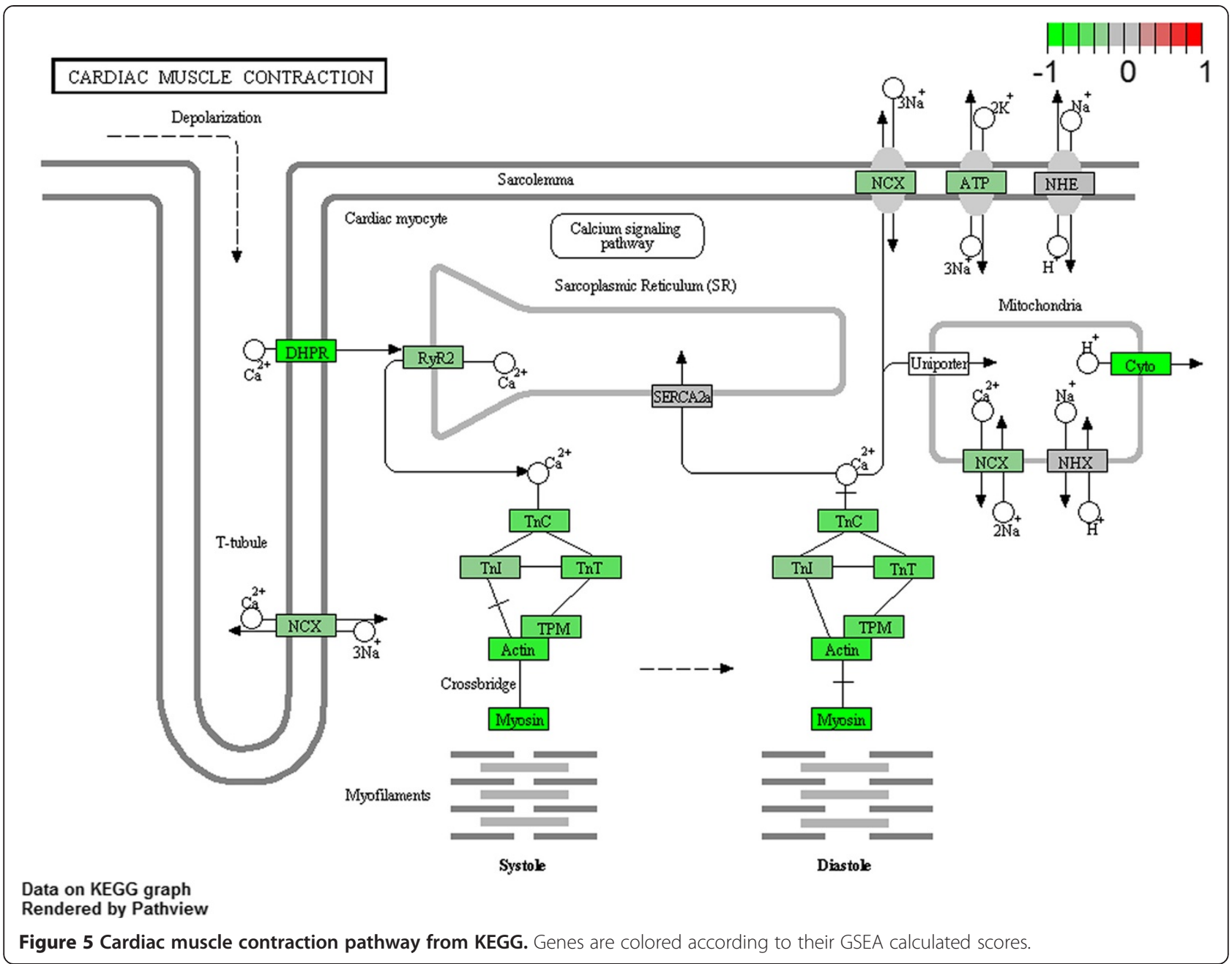

step didn't prejudice the final result as demonstrated by Peng et al. [48]. We analyzed two genes for each mentioned pathway, that were also included in the group of transcripts significantly modulated between $\mathrm{R} 6 / 2$ and WT mice in microarrays (abs FC $>1.3$ and $\mathrm{p}<0.05$ ). The selected genes consisted of C3 and Serping1, employed to test immunological hypothesis, Fabp1 together with Slc27a2 to confirm peripheral involvement of PPAR signaling, and Tmp2 and Slc8a1 for validation of cardiac dysfunction (Table 2). This selection was limited to genes with expression levels detectable by RT-qPCR.

All genes were tested by RT-qPCR on the same blood samples used for microarray assay and data were normalized on four reference genes. Normalized expression levels confirmed the modulation observed in microarray (reported in Table 2); in detail, C3, Serping1, Slc27a2, and Fabp 1 resulted up-regulated in R6/2 mutant vs WT mice, while Tpm2 and Slc8a1 showed down-regulation,

Table 2 Selected genes investigated by RT-qPCR

\begin{tabular}{|c|c|c|c|c|c|}
\hline Gene symbol & ENTREZ ID & GENE NAME & Affy Id & R6/2 vs WT FC & R6/2 vs WT $p$ \\
\hline Tpm2 & 22004 & tropomyosin 2, beta & 1425028_a_at & -1.8 & 0.016 \\
\hline Slc8a1 & 20541 & solute carrier family 8 (sodium/calcium exchanger), member 1 & 1437675_at & -1.36 & 0.047 \\
\hline C3 & 12266 & complement component 3 & 1423954_at & 4.51 & 0.000 \\
\hline Serping1 & 12258 & serine (or cysteine) peptidase inhibitor, clade G, member 1 & 1416625_at & 2.6 & 0.009 \\
\hline Slc27a2 & 26458 & solute carrier family 27 (fatty acid transporter), member 2 & 1416316_at & 3.27 & 0.000 \\
\hline Fabp1 & 14080 & fatty acid binding protein 1 , liver & 1448764_a_at & 20.35 & 0.018 \\
\hline
\end{tabular}

Table reports name, symbol and entrez ID (obtained from NCBI database) of each gene. Corresponding Affy id together with relative Fold Change (FC) and pvalue $(p)$ obtained by microarray statistical analysis (Section Methods) are also showed. 
although the last one had a small modulation (Figure 6). These results validated peripheral pathway alterations obtained by GSEA, mirroring the fold changes of microarray analysis. Moreover, our data agreed with the dysregulation of complement components that was previously observed in $\mathrm{HD}$ patients plasma [23]. On the contrary, in a recent work, C3 plasma protein level in $\mathrm{R} 6 / 2$ was found not significantly modulated [49] probably due to the different age of animals in our study with respect to theirs. To validate other candidate matrices often employed as source of biomarkers, and to compare peripheral transcriptional alterations, expression levels of the selected genes were investigated in other peripheral tissues, skeletal muscle and skin, where the presence of mut-HTT and polyQ inclusions has been demonstrated [17]. Gene expression alteration has been already investigated in HD skeletal muscle [50-52], but not yet in HD skin, although this tissue has been utilized in transcriptional studies [53]. In our study, C3 and Serping1 presented the same modulations in blood and in skin samples but these were not statistically significant (Figure 7); on the contrary, statistically significant down-regulation of these two genes was highlighted in R6/2 skeletal muscle with respect to wild type (Figure 8). Slc27a2 was not expressed in skin of wild type mice but it was quantifiable only in R6/2 (Figure 7); average up-regulation was also noticed on skeletal muscle samples but with high variability (Figure 8). Slc27a2 overexpression occurring only in mutant mice allowed us to hypothesize a probable perturbation of fatty acid metabolism in periphery. Fabp1 was not quantified in these peripheral tissues. Tpm2 and Slc8a1 were not significantly modulated in skeletal muscle or skin samples

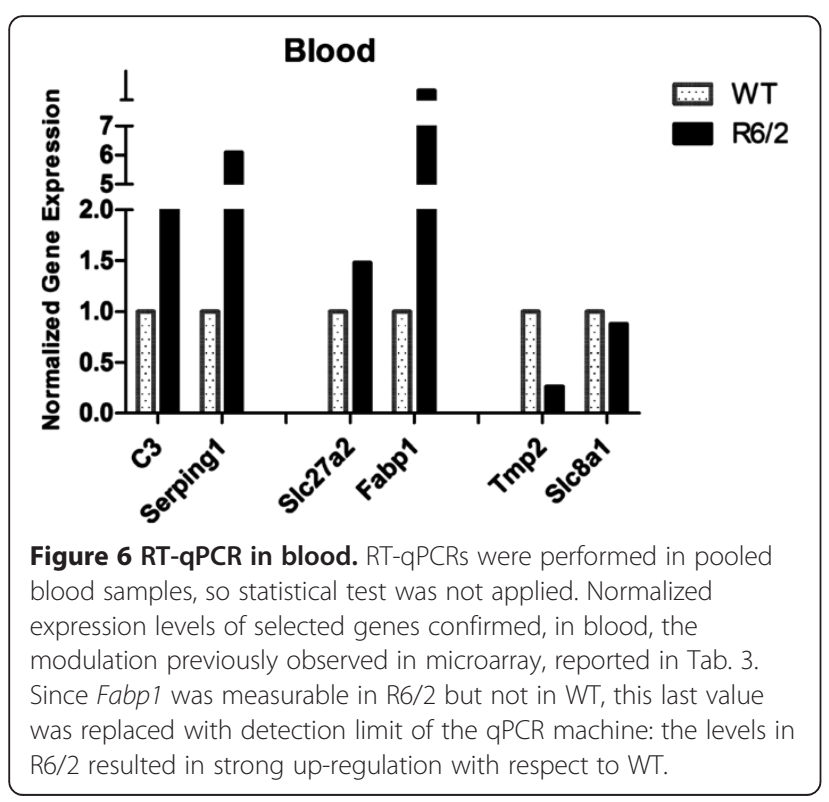

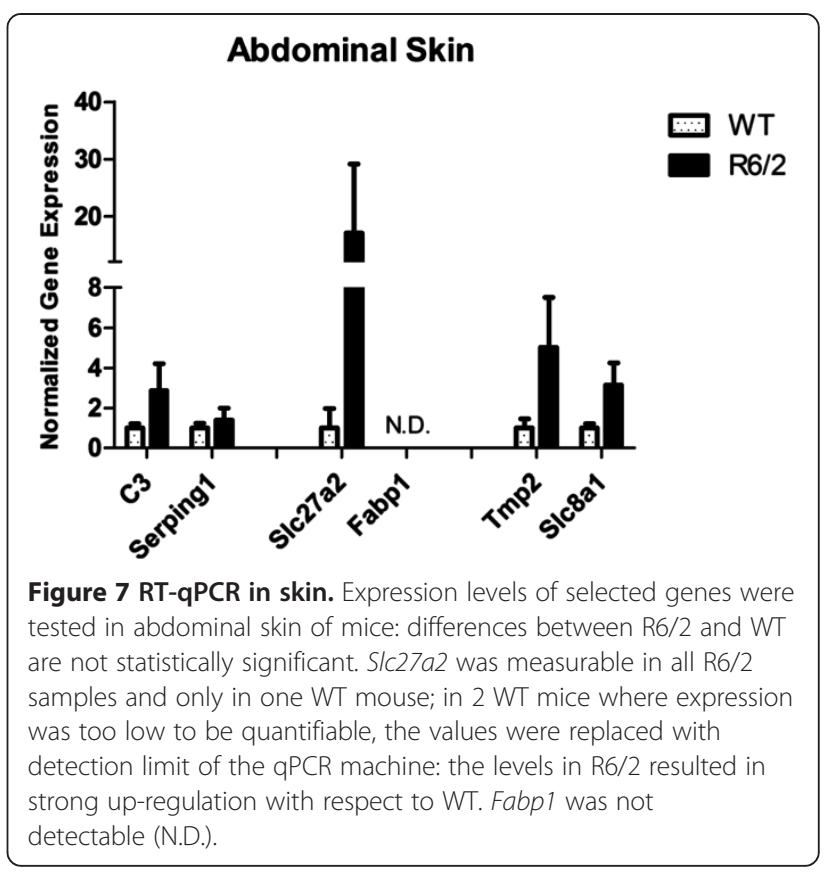

(Figure 7 and 8). Nevertheless, our data partially confirmed a transcriptional modulation for $T p m 2$, which in a previously published work [52] was included in the top 75 decreasing genes in R6/2 quadriceps muscle. Therefore, skeletal muscle may represent a suitable source to investigate peripheral transcriptional alterations; instead, the provided data were not robust enough to validate skin for this purpose. Moreover, this finding suggested that complement pathway is impaired also in skeletal muscle, and the subsequent immune response activation may contribute to muscular atrophy, together with the previously described molecular mechanisms of apoptosis and autophagy [50,52].

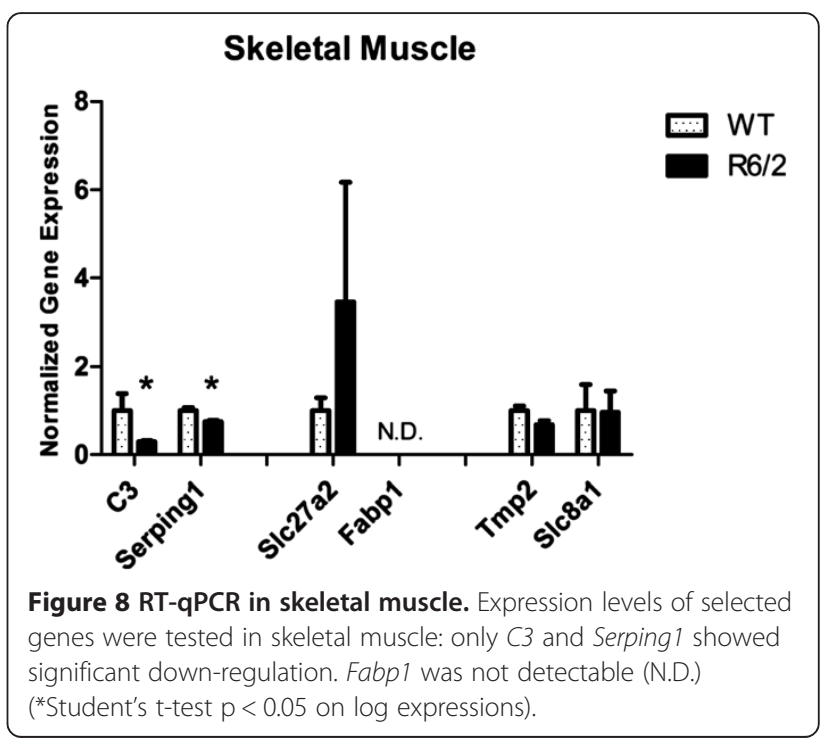


In addition, with the aim to find potential links between blood modulated pathways and the disease etiology and the molecular pathological relationship between peripheral and central tissues, gene expression levels were also analyzed in mouse brains (Figure 9). This investigation revealed that only C3, Tpm2 and Serping1 were significantly modulated in brain of $\mathrm{R} 6 / 2$, even if the last one highlighted an opposite behavior with respect to the one observed in blood; Fabp1 resulted undetectable in brain. Up-regulation of other serpins was already observed in R6/2 brain and other tissues as well as in patients brain [54]. In addition, C3 mRNA increment in $\mathrm{R} 6 / 2$ brains mirrored results of transcriptional investigations displaying an increased complement biosynthesis in different brain areas of HD patients compared to healthy individuals [28,55] but again differed from Larkin et al. [49] that did not observe significant $C 3$ expression modulation in $R 6 / 2$ brain. Our data raise the possibility of therapies targeting complement components in neurodegenerative disorder, with probably Serping1 representing, with respect to $C 3$, a better candidate disease target in terms of drug development, and a potential biomarker [30,31].

In conclusion, all these findings enforce the hypothesis that immunological alteration may contribute to neurological degeneration and components of this pathway may represent potential biomarkers to monitor in parallel drug efficacy in periphery and in brain, supporting the usefulness of this model in pre-clinical studies.

\section{Conclusion}

HD is a neurological and devastating disorder with an urgent need of effective therapies and well established biomarkers. Even though major efforts in finding peripheral disease progression biomarkers are pursued in

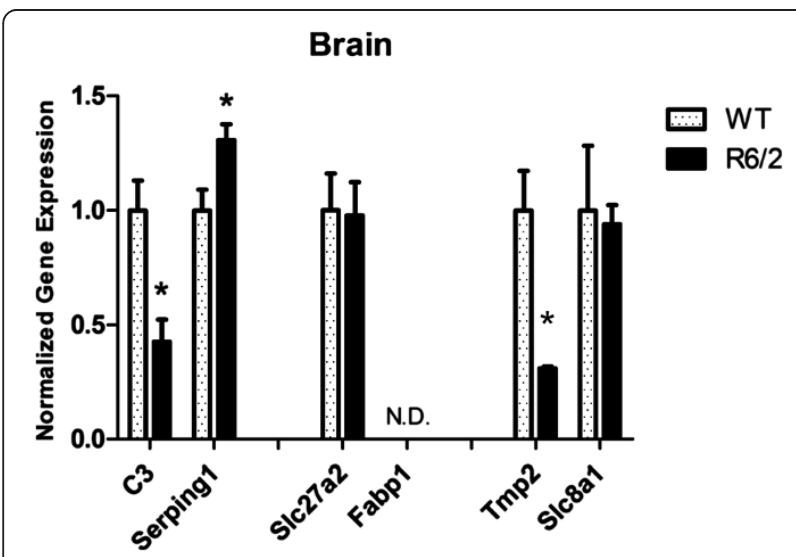

Figure 9 RT-qPCR in brain. Normalized expression levels of selected genes showed that C3 and Serping1 were modulated but in opposite direction, and Tmp2 was down-regulated. Fabp1 was not detectable (N.D.) ( ${ }^{*}$ Student's t-test $p<0.05$ on log expressions). human studies, the availability of validated animal disease models is of great aid in all pre-clinical studies aimed at moving ahead promising compounds into clinical studies, evaluating their possible molecular mechanism of action. In addition, transcriptional analysis on these models could unveil novel therapeutic targets related to the pathology onset and progression.

On the other side, one of the major drawbacks for in-vivo pathology models is the incomplete correspondence of these with the real human disease situation that could cause misinterpretation of data, with deleterious effects on drug discovery progression. Here, we evaluated through a whole genome approach, peripheral transcriptional alterations of biological pathways in circulating blood cells of a well characterized HD mouse model. Our data revealed the direct involvement of processes that are well known markers of Huntington's disease progression in man. Several microarray findings have been investigated by RT-qPCR in other peripheral easily accessible tissues and in brain with obvious projection toward clinical studies. The approach adopted in this work offers interesting remarks that could be further investigated in a larger cohort of transgenic mice at different stages of pathology development and validated in other HD models to strengthen the findings on the involvement in HD progression of these biological pathways obtained by GSEA analysis. Nevertheless, preliminary results presented here could be considered a further step in validating the $\mathrm{R} 6 / 2$ mouse model as first line pre-clinical tool, giving at the same time an insight of important pathological hallmarks for Huntington's disease, and contributing to attractive novel biomarkers development.

\section{Methods}

\section{Mouse handling, blood and tissues collection}

This study included four R6/2 male mice (about 110 CAG repeats) and four wild type (WT) male littermates that were bred at PsychoGenics Laboratories (Tarrytown, NY, USA). All animals were examined, manipulated, and weighed prior initiation of the study to assure adequate health, suitability and to minimize non-specific stress associated with manipulation. During the course of the study animals were maintained in a 12/12 light/dark cycles with temperature ranging between 20 and $23^{\circ} \mathrm{C}$ and relative humidity around $50 \%$. Chow and water were provided ad libitum for the duration of the study. Genotype was determined by PCR analysis of DNA tail, performed at PsychoGenics Laboratories.

Mice were sacrificed at the age of 16 weeks. Terminal whole blood samples were collected via closed cardiac puncture on anesthetized live mouse $\left(\mathrm{CO}^{2}\right)$. Blood samples were drawn by sterile syringe and $100 \mu \mathrm{l}$ were directly transferred to RNAprotect Animal Blood Tubes 
(BD QIAGEN cat $n^{\circ} 76544$ ) according to the manufacturer indications and maintained at $-80^{\circ} \mathrm{C}$. In addition, the following organs were collected: brain with cerebellum, skeletal muscle (quadriceps) and skin (a strip of about $1 \mathrm{~cm} \times 3 \mathrm{~cm}$ of the abdominal area).

All experiments on mice were carried out in strict accordance with the recommendations of the Guide for the Care and Use of Laboratory Animals. The protocol was approved by the Institutional Animal Care and Use Committee of PsychoGenics, Inc. (PHS OLAW animal welfare assurance number A4471-01), an AAALAC International accredited institution (Unit \#001213).

\section{RNA purification}

Total RNA was purified from whole blood by RNeasy Protect animal blood kit (QIAGEN GmbH, Hilden, Germany) according to the instruction provided with the kit. Purified RNA was quantified by Nanodrop ND1000 Spectrophotometer and checked for RNA integrity by Bioanalyzer (Agilent Technologies, Palo Alto, CA). All samples with RIN between 8.40 and 9.0 were included in the subsequent investigations: RNA obtained from blood of a wild type mouse did not satisfy quality control and was excluded from transcriptional investigations ( $\mathrm{RIN}=7.50)$.

Total RNA was extracted from brain (ensuring to dissect exactly the same portion, including striatum and cortex), skeletal muscle, and skin after shaving using RNeasy Lipid Tissue Mini kit (QIAGEN) following the instruction provided by the kit.

To assess RNA integrity (28S and $18 \mathrm{~S}$ ribosomal RNA bands) all samples were loaded on agarose gel with Ethidium Bromide (Sigma-Aldrich Corporation, MO, USA) and quantified by NANODROP 2000 spectrophotometer (Thermo Fischer Scientific, MA, USA).

\section{Gene expression analysis Microarray}

Microarray experiment was performed on individual blood samples, $500 \mathrm{ng}$ of total RNA of each sample was employed to generate target RNA or amplified RNA (aRNA). This aRNA was then hybridized onto GeneChip ${ }^{\circ}$ Mouse Genome 430 2.0. This array comprises over
45,000 probe sets representing more than 34,000 wellsubstantiated mouse genes. Microarrays experiment was performed by Precision Biomarker Resources, Inc. (Evanston, IL, USA).

\section{$R T-q P C R$}

Before cDNA synthesis, the same quantity of RNAs derived from every blood sample of each strain was pooled together obtaining a single pooled sample of wild type mice blood and a single pooled sample of mutant mice blood. The two deriving pools were quantified by NANODROP 2000 Spectrophotometer (Thermo Fischer Scientific, MA, USA). cDNA was synthesized from $1 \mu \mathrm{g}$ of RNA obtained from blood pooled samples as well as from all the other individual tissues (brain, skeletal muscle and skin), by using QuantiTect Reverse Transcription kit (QIAGEN GmbH, Hilden, Germany) and diluted to $100 \mu \mathrm{L}$.

RT-qPCRs on cDNA samples were performed using a CFX96 Real Time System/C1000 Thermal cycler (BioRad Hercules, CA, USA) with $\mathrm{iQ}^{\mathrm{Tm}}$ SYBR Green master mix 2X (Bio-Rad) with primers that specifically amplified target or control genes. The run protocol used in RT-qPCR was the " 2 step amplification", with annealing temperature tailored on the primer pair used. Each run was followed by Melting Curve run and analysis to confirm amplification of a single product.

The primers were designed using Beacon Designer 7.9 software (PREMIER Biosoft International, CA, USA), employing sequences data from NCBI database or from published validated sequences. To guarantee primer specificity, they were checked with NCBI BLAST against Reference RNA sequence (Refseq_rna) of Mus musculus. Primers were defined inside the region targeted by Affymetrix probe sets. Complete primer sequences, gene bank accession numbers are shown in Table 3. RT-qPCR expression data on blood samples were normalized on geometric mean of Ppib, Actb, Ywhaz and Rpl13a, as described elsewhere [16]. Moreover, Actb, B2m, Hprt, and $R p l 13 a$ were employed for the other tissues, except $A c t b$ in skeletal muscle (due to low stability, data not shown). Reference gene primer sequences were taken from Diamanti et al. [16].

Table 3 Complete primer sequences and gene bank accession numbers of selected genes analyzed in RT-qPCR

\begin{tabular}{llll}
\hline Gene symbol & Ref seq & Primer sequence Forward & Primer sequence Reverse \\
\hline C3 & K02782, NM_009778 & GGTGTGCTGAAGAGAACT & TGAGCCTGACTTGATGAC \\
Serping1 & NM_009776 & AAAGTAAAGAGCAGCCAAGACA & CAGGTTGAGATCGTAAGTGAAGT \\
Slc27a2 & NM_011978 & TGAAGAAGTGAATGTGTATGG & TCTCAATGGTATCTTGTATCCT \\
Fabp1 & NM_017399 & CGTGACTGAACTCAATGG & TTCTCTTGCTGACTCTCTT \\
Slc8a1 & NM_011406 & TCCATCCAGTAGACTTCGTGAT & CCAAGCAATTCCTTACAGAGTGA \\
Tmp2 & NM_009416 & AGCCCAAGCGGACAAGTA & CGGGTCTCAGCCTCTTCA \\
\hline
\end{tabular}




\section{Bioinformatics and statistical analyses}

Affymetrix CEL files were analyzed with $\mathrm{R}$ program (The R Project for Statistical Computing http://www.r-project. org/) by making use of Bioconductor packages (http:// www.bioconductor.org). Normalization for quantitative comparison of different microarrays was performed with quantiles within the RMA package [56-58] and final expression values were calculated by summarizing probe set intensities with median-Polish algorithm. Differential expression analysis between four mutant and three wild type samples was tested with LIMMA package [59]. Correction for multiple testing was not performed due to the low number of arrays.

In $\mathrm{RT}-\mathrm{qPCR}$, relative expressions, obtained from $\mathrm{Cq}$ corrected by amplification efficiency, were normalized on geometric mean of selected reference gene expression values [16].

Differentially modulated genes in brain, skin and muscle among mutant and wild type samples were identified with Student's t-test on logarithmic transformed expressions, p-values below 0.05 were considered statistically significant. No statistical test was applied on blood samples, because these samples were pooled in RT-qPCR investigations. Statistical analysis of RT-qPCR data was performed in GraphPad Prism 5.

Gene set enrichment analysis of microarray data was performed using GSEA 2.07 software ( [60], http://www. broadinstitute.org/gsea/index.jsp) and using MSigDB v 3.1, focusing attention on the following collections: $\mathrm{C} 2$ BioCarta gene sets, C2 KEGG gene sets, C2 Reactome gene sets and C5 GO Biological Processes. Software default parameters were used, except for permutation type parameter that was set to "permutation on gene set" due to the low number of arrays employed. Gene sets with false discovery rate (FDR) less than 0.25 were considered significant.

KEGG pathways were downloaded and processed in R/Bioconductor by using Pathview package [61].

\section{Additional files}

\section{Additional file 1: Enriched GO Biological Process collection.}

Description: Table showed Biological Processes enriched in R6/2 (in red) or in WT (in green) and GSEA results.

Additional file 2: Complement and Coagulation Cascades Pathway members part of the core enrichment. Description: Annotations of genes with corresponding Affy Id are reported together with GSEA statistic (enrichment score, ES) and LIMMA statistics (fold change, FC, and p-value.

Additional file 3: PPAR Signaling Pathway members part of the core enrichment. Description: Annotations of genes with corresponding Affy Id are reported for PPAR signaling pathway; GSEA statistic (enrichment score, ES) and LIMMA statistics (fold change, FC, and p-value) are also showed

Additional file 4: Cardiac Muscle Contraction Pathway members part of the core enrichment. Description: Annotations of genes with corresponding Affy Id are reported together with GSEA statistic (enrichment score, ES) and LIMMA statistics (fold change, FC, and p-value) for Cardiac Muscle Contraction pathway.

Additional file 5: Dilated Cardiomyopathy Pathway members part of the core enrichment. Description: Annotations of genes with corresponding Affy Id are reported together with GSEA statistic (enrichment score, ES) and LIMMA statistics (fold change, FC, and p-value) for Dilated Cardiomyopathy pathway.

\section{Competing interests}

The authors declare that they have not competing interests.

\section{Authors' contributions}

DD, DI, CF carried out the transcriptional studies. FM performed functional genomics analysis on probe sets and participated in primer design. EM applied GSEA methods on microarrays data and performed qPCR statistical analysis. LM performed the microarrays statistical analysis. DD and GP conceived the study, and participated in its design and coordination. All authors contributed in preparing the draft manuscript and approved the final version.

\section{Acknowledgments}

This work has been supported by European Union - PADDINGTON project, contract n. HEALTH-F2-2010-261358. (http://www.paddingtonproject.eu/). We thank Giovanna Tripepi and Enrica Diodato for PADDINGTON project management and Carla Scali for guidance in animal models.

\section{Author details}

${ }^{1}$ Siena Biotech S.p.A., strada del Petriccio e Belriguardo, Siena 35, 53100, Italy. ${ }^{2}$ HuGeF (Human Genetics Foundation), via Nizza 52, Torino, Italy.

Received: 8 August 2013 Accepted: 15 October 2013

Published: 23 October 2013

\section{References}

1. Roos RAC: Huntington's disease: a clinical review. Orphanet J Rare Dis 2010, 5(1):40.

2. Soulet $D$, Cicchetti $F$ : The role of immunity in Huntington's disease. Mol Psychiatry 2011, 16(9):889-902.

3. Aziz NA, Swaab DF, Pijl H, Roos RAC: Hypothalamic dysfunction and neuroendocrine and metabolic alterations in Huntington's disease: clinical consequences and therapeutic implications. Rev Neurosci 2007, 18(3-4):223-251.

4. Zuccato C, Valenza M, Cattaneo E: Molecular mechanisms and potential therapeutical targets in Huntington's disease. Physiol Rev 2010, 90(3):905-981.

5. Kazantsev AG, Hersch SM: Drug targeting of dysregulated transcription in Huntington's disease. Prog Neurobiol 2007, 83(4):249-259.

6. Seredenina $T$, Luthi-Carter $R$ : What have we learned from gene expression profiles in Huntington's disease? Neurobiol Dis 2012, 45(1):83-98.

7. Benn CL, Sun T, Sadri-Vakili G, McFarland KN, DiRocco DP, Yohrling GJ, Clark TW, Bouzou B, Cha JHJ: Huntingtin modulates transcription, occupies gene promoters in vivo, and binds directly to DNA in a polyglutaminedependent manner. J Neurosci 2008, 28(42):10720-10733.

8. Steffan JS, Kazantsev A, Spasic-Boskovic O, Greenwald M, Zhu YZ, Gohler H, Wanker EE, Bates GP, Housman DE, Thompson LM: The Huntington's disease protein interacts with $\mathrm{p} 53$ and CREB-binding protein and represses transcription. Proc Natl Acad Sci U S A 2000, 97(12):6763-6768.

9. Ehrnhoefer DE, Butland SL, Pouladi MA, Hayden MR: Mouse models of Huntington disease: variations on a theme. Dis Model Mech 2009, 2(3-4):123-129.

10. Ferrante RJ: Mouse models of Huntington's disease and methodological considerations for therapeutic trials. Biochim Biophys Acta 2009, 1792(6):506-520

11. Crook ZR, Housman D: Huntington's disease: can mice lead the way to treatment? Neuron 2011, 69(3):423-435.

12. Vonsattel JPG: Huntington disease models and human neuropathology: similarities and differences. Acta Neuropathol 2008, 115(1):55-69.

13. Mangiarini L, Sathasivam K, Seller M, Cozens B, Harper A, Hetherington C, Lawton M, Trottier Y, Lehrach H, Davies S, Bates G: Exon 1 of the HD gene 
with an expanded CAG repeat is sufficient to cause a progressive neurological phenotype in transgenic mice. Cell 1996, 87:493-506.

14. Ribchester RR, Thomson D, Wood NI, Hinks T, Gillingwater TH, Wishart TM, Court FA, Morton AJ: Progressive abnormalities in skeletal muscle and neuromuscular junctions of transgenic mice expressing the Huntington's disease mutation. Eur J Neurosci 2004, 20(11):3092-3114.

15. Strand $A D$, Aragaki $A K$, Baquet $Z C$, Hodges $A$, Cunningham $P$, Holmans $P$, Jones KR, Jones L, Kooperberg C, Olson JM: Conservation of regional gene expression in mouse and human brain. PLoS Genet 2007, 3(4):e59.

16. Diamanti D, Lahiri N, Tarditi A, Magnoni L, Fondelli C, Morena E, Malusa F, Pollio G, Diodato E, Tripepi G, Tabrizi SJ, Caricasole A, Mori E: Reference genes selection for transcriptional profiling in blood of HD patients and R6/2 mice. Journal of Huntington's Disease 2013, 2(2):185-200.

17. Moffitt H, McPhail GD, Woodman B, Hobbs C, Bates GP: Formation of polyglutamine inclusions in a wide range of non-CNS tissues in the HdhQ150 knockin mouse model of Huntington's disease. PLoS One 2009, 4(11):e8025.

18. van der Burg JMM, Björkqvist M, Brundin P: Beyond the brain: widespread pathology in Huntington's disease. Lancet Neurol 2009, 8(8):765-774.

19. Björkqvist M, Wild EJ, Thiele J, Silvestroni A, Andre R, Lahiri N, Raibon E, Lee RV, Benn CL, Soulet D, Magnusson A, Woodman B, Landles C, Pouladi MA, Hayden MR, Khalili-Shirazi A, Lowdell MW, Brundin P, Bates GP, Leavitt BR, Möller T, Tabrizi SJ: A novel pathogenic pathway of immune activation detectable before clinical onset in Huntington's disease. J Exp Med 2008, 205(8):1869-1877.

20. Borovecki F, Lovrecic L, Zhou J, Jeong H, Then F, Rosas HD, Hersch SM, Hogarth P, Bouzou B, Jensen RV, Krainc D: Genome-wide expression profiling of human blood reveals biomarkers for Huntington's disease. Proc Natl Acad Sci U S A 2005, 102(31):11023-11028.

21. Runne H, Kuhn A, Wild EJ, Pratyaksha W, Kristiansen M, Isaacs JD, Régulier E, Delorenzi M, Tabrizi SJ, Luthi-Carter R: Analysis of potential transcriptomic biomarkers for Huntington's disease in peripheral blood. Proc Natl Acad Sci U S A 2007, 104(36):14424-14429.

22. Conforti P, Ramos C, Apostol BL, Simmons DA, Nguyen HP, Riess O, Thompson LM, Zuccato C, Cattaneo E: Blood level of brain-derived neurotrophic factor mRNA is progressively reduced in rodent models of Huntington's disease: restoration by the neuroprotective compound CEP-1347. Mol Cell Neurosci 2008, 39(1):1-7.

23. Dalrymple A, Wild EJ, Joubert R, Sathasivam K, Björkqvist M, Petersén A, Jackson GS, Isaacs JD, Kristiansen M, Bates GP, Leavitt BR, Keir G, Ward M Tabrizi SJ: Proteomic profiling of plasma in Huntington's disease reveals neuroinflammatory activation and biomarker candidates. J Proteome Res 2007, 6(7):2833-2840.

24. Underwood BR, Broadhurst D, Dunn WB, Ellis DI, Michell AW, Vacher C Mosedale DE, Kell DB, Barker RA, Grainger DJ, Rubinsztein DC: Huntington disease patients and transgenic mice have similar pro-catabolic serum metabolite profiles. Brain 2006, 129(Pt 4):877-886.

25. Carroll MV, Sim RB: Complement in health and disease. Adv Drug Deliv Rev 2011, 63(12):965-975.

26. Francis K, van Beek J, Canova C, Neal JW, Gasque P: Innate immunity and brain inflammation: the key role of complement. Expert Rev Mol Med 2003, 5(15):1-19.

27. Nayak A, Ansar R, Verma SK, Bonifati DM, Kishore U: Huntington's disease: an immune perspective. Neurol Res Int 2011, 2011:563784.

28. Singhrao SK, Neal JW, Morgan BP, Gasque P: Increased complement biosynthesis by microglia and complement activation on neurons in Huntington's disease. Exp Neurol 1999, 159(2):362-376.

29. Wild E, Magnusson A, Lahiri N, Krus U, Orth M, Tabrizi SJ, Björkqvist M: Abnormal peripheral chemokine profile in Huntington's disease. PLoS Curr 2011, 3, RRN1231.

30. Wagner E, Frank MM: Therapeutic potential of complement modulation. Nat Rev Drug Discov 2010, 9(1):43-56.

31. Ricklin D, Lambris JD: Complement-targeted therapeutics. Nat Biotechnol 2007 25(11):1265-1275.

32. Kiaei M: Peroxisome proliferator-activated receptor-gamma in amyotrophic lateral sclerosis and Huntington's disease. PPAR Res 2008, 2008:418765.

33. Phan J, Hickey MA, Zhang P, Chesselet MF, Reue K: Adipose tissue dysfunction tracks disease progression in two Huntington's disease mouse models. Hum Mol Genet 2009, 18(6):1006-1016.

34. Valenza M, Cattaneo E: Emerging roles for cholesterol in Huntington's disease. Trends Neurosci 2011, 34(9):474-486
35. Valenza M, Cattaneo E: Cholesterol dysfunction in neurodegenerative diseases: is Huntington's disease in the list? Prog Neurobiol 2006, 80(4):165-176

36. Block RC, Dorsey ER, Beck CA, Brenna JT, Shoulson I: Altered cholesterol and fatty acid metabolism in Huntington disease. J Clin Lipidol 2010, 4(1):17-23.

37. Zündorf $\mathrm{G}$, Reiser $\mathrm{G}$ : Calcium dysregulation and homeostasis of neural calcium in the molecular mechanisms of neurodegenerative diseases provide multiple targets for neuroprotection. Antioxid Redox Signal 2011, 14(7):1275-1288

38. Bezprozvanny I, Hayden MR: Deranged neuronal calcium signaling and Huntington disease. Biochem Biophys Res Commun 2004, 322(4):1310-1317.

39. Jin YN, Johnson GWW: The interrelationship between mitochondrial dysfunction and transcriptional dysregulation in Huntington disease. Journal of bioenergetics and biomembranes 2010, 42(3):199-205.

40. Lim D, Fedrizzi L, Tartari M, Zuccato C, Cattaneo E, Brini M, Carafoli E: Calcium homeostasis and mitochondrial dysfunction in striatal neurons of Huntington disease. J Biol Chem 2008, 283(9):5780-5789.

41. Damiano M, Galvan L, Déglon N, Brouillet E: Mitochondria in Huntington's disease. Biochim Biophys Acta 2010, 1802(1):52-61.

42. Lesnefsky EJ, Moghaddas S, Tandler B, Kerner J, Hoppel CL: Mitochondrial dysfunction in cardiac disease: ischemia-reperfusion, aging, and heart failure. Journal of molecular and cellular cardiology 2001, 33(6):1065-1089.

43. Sorensen SA, Fenger K: Causes of death in patients with Huntington's disease and in unaffected first degree relatives. Journal of medical genetics 1992, 29(12):911-914.

44. Wood NI, Sawiak SJ, Buonincontri G, Niu Y, Kane AD, Carpenter AT, Giussani DA, Morton AJ: Direct evidence of progressive cardiac dysfunction in a transgenic mouse model of Huntington's disease. Journal of Huntington's Disease 2012, 1(1):57-64

45. Mihm MJ, Amann DM, Schanbacher BL, Altschuld RA, Bauer JA, Hoyt KR: Cardiac dysfunction in the R6/2 mouse model of Huntington's disease. Neurobiol Dis 2007, 25(2):297-308

46. Aziz H, Zaas A, Ginsburg GS: Peripheral blood gene expression profiling for cardiovascular disease assessment. Genomic Medicine 2007, 1(3-4):105-112.

47. Mohr S, Liew CC: The peripheral-blood transcriptome: new insights into disease and risk assessment. Trends Mol Med 2007, 13(10):422-432.

48. Peng X, Wood CL, Blalock EM, Chen KC, Landfield PW, Stromberg AJ: Statistical implications of pooling RNA samples for microarray experiments. BMC Bioinforma 2003, 4:26.

49. Larkin PB, Muchowski PJ: Genetic deficiency of complement component 3 does not alter disease progression in a mouse model of Huntington's disease. J Huntingtons Dis 2012, 1(1):107-118.

50. She P, Zhang Z, Marchionini D, Diaz WC, Jetton TJ, Kimball SR, Vary TC, Lang $\mathrm{CH}$, Lynch CJ: Molecular characterization of skeletal muscle atrophy in the R6/2 mouse model of Huntington's disease. Am J Physiol Endocrinol Metab 2011, 301(1):E49-E61.

51. Luthi-Carter R, Hanson SA, Strand AD, Bergstrom DA, Chun W, Peters NL, Woods AM, Chan EY, Kooperberg C, Krainc D, Young AB, Tapscott SJ, Olson $J M$ : Dysregulation of gene expression in the R6/2 model of polyglutamine disease: parallel changes in muscle and brain. Hum $\mathrm{Mol}$ Genet 2002, 11(17):1911-1926.

52. Strand AD, Aragaki AK, Shaw D, Bird T, Holton J, Turner C, Tapscott SJ, Tabrizi SJ, Schapira AH, Kooperberg C, Olson JM: Gene expression in Huntington's disease skeletal muscle: a potential biomarker. Hum Mol Genet 2005, 14(13):1863-1876.

53. Greco 3J, Pollins AC, Boone BE, Levy SE, Nanney LB: A microarray analysis of temporal gene expression profiles in thermally injured human skin. Burns 2010, 36(2):192-204.

54. Zabel C, Chamrad DC, Priller J, Woodman B, Meyer HE, Bates GP, Klose J: Alterations in the mouse and human proteome caused by Huntington's disease. Mol Cell Proteomics 2002, 1(5):366-375.

55. Hodges A, Strand AD, Aragaki AK, Kuhn A, Sengstag T, Hughes G, Elliston LA, Hartog C, Goldstein DR, Thu D, Hollingsworth ZR, Collin F, Synek B, Holmans PA, Young AB, Wexler NS, Delorenzi M, Kooperberg C, Augood S. Faull RLM, Olson JM, Jones L, Luthi-Carter R: Regional and cellular gene expression changes in human Huntington's disease brain. Hum Mol Genet 2006, 15(6):965-977.

56. Gentleman RC, Carey VJ, Bates DM, Bolstad B, Dettling M, Dudoit S, Ellis B, Gautier L, Ge Y, Gentry J, Hornik K, Hothorn T, Huber W, lacus S, Irizarry R, 
Leisch F, Li C, Maechler M, Rossini AJ, Sawitzki G, Smith C, Smyth G, Tierney $L$, Yang JYH, Zhang J: Bioconductor: open software development for computational biology and bioinformatics. Genome Biol 2004, 5(10):R80.

57. Irizarry RA, Bolstad BM, Collin F, Cope LM, Hobbs B, Speed TP: Summaries of affymetrix genechip probe level data. Nucleic Acids Res 2003, 31(4):e15.

58. Bolstad BM, Irizarry RA, Astrand M, Speed TP: A comparison of normalization methods for high density oligonucleotide array data based on variance and bias. Bioinformatics 2003, 19(2):185-193.

59. Smyth GK: Linear models and empirical Bayes methods for assessing differential expression in microarray experiments. Stat Appl Genet Mol Biol 2004, 3. article 3 .

60. Subramanian A, Tamayo P, Mootha VK, Mukherjee S, Ebert BL, Gillette MA, Paulovich A, Pomeroy SL, Golub TR, Lander ES, Mesirov JP: Gene set enrichment analysis: a knowledge-based approach for interpreting genome-wide expression profiles. Proc Natl Acad Sci U S A 2005, 102(43):15545-15550.

61. Luo W, Brouwer C: Pathview: an R/Bioconductor package for pathwaybased data integration and visualization. Bioinformatics 2013, 29(14):1830-1831.

doi:10.1186/2050-7771-1-28

Cite this article as: Diamanti et al:: Whole gene expression profile in blood reveals multiple pathways deregulation in R6/2 mouse model. Biomarker Research 2013 1:28.

\section{Submit your next manuscript to BioMed Central and take full advantage of:}

- Convenient online submission

- Thorough peer review

- No space constraints or color figure charges

- Immediate publication on acceptance

- Inclusion in PubMed, CAS, Scopus and Google Scholar

- Research which is freely available for redistribution 